\title{
Sample size and prediction of weight and yield of individual cuts from Braford steers
}

\section{pistol hindquarters}

\author{
Leandro Lunardini Cardoso ${ }^{1 *} \odot$, Jaime Urdapilleta Tarouco ${ }^{1 \oplus}$, Michael D. MacNeil2๑, José Fernando Piva Lobato ${ }^{1}$, Mara Célia \\ Dambrós $^{3 \oplus}$, Aline Kellermann de Freitas ${ }^{1} \odot$, Thais Devincenzi ${ }^{\circledR}$, Fernanda Dorneles Feijó ${ }^{1}{ }^{\oplus}$, Fernando Flores Cardoso ${ }^{4}$
}

\author{
'Universidade Federal do Rio Grande do Sul/FAEM - Depto. \\ de Zootecnia, Av. Bento Gonçalves, 7712 - 91540-000 - \\ Porto Alegre, RS - Brasil. \\ 2Delta G, 145 Ice Cave Rd., Miles City, Montana, MT, United \\ States. \\ 3Universidade Federal de São Paulo, R. Sena Madureira, \\ 1500 - 040201-001 - São Paulo, SP - Brasil. \\ ${ }^{4}$ Embrapa Pecuária Sul, BR-153, km 603 - 96401-970 - \\ Bagé, RS - Brasil. \\ *Corresponding author <lunardini.cardoso@ufrgs.br>
}

Edited by: Gerson Barreto Mourão

Received July 13, 2018

Accepted January 28, 2019
ABSTRACT: Two hundred seventeen grass-finished Braford steers were assessed by ultrasonic scanning and subsequently harvested with their pistol hindquarters fabricated into boneless wholesale cuts. The Longissimus thoracis muscle area and subcutaneous fat depths were measured. The objectives of this study were: 1) to develop prediction equations for weights of the pistol hindquarter and high-value commercial cuts, and 2) to estimate sample size needed for experiments comparing pistol hindquarter retail product weight using either physically or ultrasonically measured carcass traits. Carcass measurements explained $44 \%$ to $94 \%$ of the variation in weights of individual cuts, whereas, measurements that were made using ultrasound explained $42 \%$ to $90 \%$ of the variation in the weights. Models used to predict the weight of pistol hindquarter retail product with carcass measures and ultrasound measures showed high coefficient of determination $\left(R^{2}=0.92\right.$ and 0.97 , respectively). Whether based on carcass or ultrasound measures, models used to estimate weight percentage of fat trimmed from the pistol hindquarter had lack of fit. In general, models for individual cuts weights that used traits measured with ultrasound as independent variables approached the accuracy of models using carcass traits. Thus, only slightly greater samples sizes were required to have equivalent power to detect differences in retail product weights using ultrasound measures. For experiments of equivalent power, differences in the number of animals required may be offset by avoiding costs for slaughter and fabrication.

Keywords: cattle, carcass, models, ultrasound

\section{Introduction}

Prediction of weights of individual cuts may provide a viable alternative for estimating value (Jardim et al., 1991; Teira et al., 2003) and aide in marketing to niches. Selection of independent variables for estimating either weight or yield of the product should include assessment of the difficulty and cost of taking the measurements, and their precision and reliability (Hedrick, 1983).

Further, with cattle fed on grass, subcutaneous fat depth is usually less at harvest than that normally observed in feedlot finished cattle (Kerth et al., 2007). Beef for export from Brazil to the European Economic Community must originate from animals raised exclusively on pasture, gives clear guidance on this issue (EC, No 810/2008). Relatively few studies have assessed regression models to estimate weight and yield of beef cuts from cattle finished on grass (Hopkins and Roberts, 1995). Consequently, a better understanding of fat and muscle deposition by grass-finished cattle may improve the quality of information used in the valuation of carcasses from Brazil. Use of indicator traits to reduce the cost of data collection is a well-accepted practice in genetic evaluation of livestock (Mark et al., 2007; MacNeil and Northcutt, 2008). For ethical and economic reasons, sound experimental design requires use of the minimum number of animals necessary to achieve a desired objective given the required precision (Festing and Altman, 2002).
In the assessment of beef carcasses, differences in a number of animals required for experiments using ultrasound for measuring phenotypes versus those using carcass traits commonly collected after harvest differ in their costs and the former obviate the need for slaughter.

Thus, knowledge of required sample sizes to achieve a pre-determined power-of-the-test for hypotheses regarding weight and yield of beef cuts with each of these paradigms can lead to perceived ethical benefits and reduced cost of experimentation and access of carcass composition. Therefore, the objectives of this study were to develop prediction equations using carcass and ultrasound measures for weight and yield of the pistol hindquarter and individual retail cuts contained therein from animals raised exclusively on pasture, and to estimate the number of experimental units required to achieve equal power-of-the-test when the experimental paradigm is based on these alternatives.

\section{Materials and Methods}

The 217 commercial Braford steers used in this study were managed following conventional industry standards as prescribed in the Guide for the Care and Use of Agricultural Animals in Research and Teaching (FASS, 2010). The animals were sampled from two datasets that included those in the study $(\mathrm{n}=111)$ of Tarouco et al. (2007) and an industrial dataset $(\mathrm{n}=106)$ the animals represent the range of potential fabrication 
weights and yields expected within the Brazilian beef population. They continuously grazed natural pasture enhanced with spring/winter species (Lolium multiflorum, Trifolium repens, and Lotus corniculatus). During finishing, the last 125 days on pasture, the steers gained an average of $1.116 \pm 0.16 \mathrm{~kg} \mathrm{~d}^{-1}$. Prior to slaughter, at $22.79 \pm 3.68$ months of age, the steers were held without feed for 12-h. Their average shrunk body weight (SBW) was $400.27 \pm$ $82.60 \mathrm{~kg}$.

Steers were weighed and ultrasonically evaluated $48 \mathrm{~h}$ before slaughter. An ALOKA SSD-500 unit, with a $17.2-\mathrm{cm}, 3.5 \mathrm{MHz}$ linear probe model UST-5044 was used to collect the images. The images were recorded, stored, and saved using the Lince ${ }^{\circledR}$ software for ultrasound image capture and analysis system, Longissimus thoracis muscle area (ULMA) and subcutaneous fat thickness (UFAT) were measured between the $12^{\text {th }}$ and the $13^{\text {th }}$ ribs. The UFAT measurement was at $3 / 4$ of the lateral distance across the Longissimus thoracis. Vegetable oil was used as an acoustic coupling for recording the ULMA and UFAT images and an acoustic rule (standoff) was used to facilitate contact between the transducer and the back of the animal. The images were recorded by an Ultrasound Guidelines Council (UGC) certified technician. Images were interpreted by an UGC-certified laboratory technician using the Lince ${ }^{\circledR}$ software for ultrasound image capture and analysis system.

The steers were slaughtered at the commercial slaughterhouse in Bagé, Rio Grande do Sul, Brazil, 166 and $65 \mathrm{~km}$ distant from the farms where they were raised. Hot carcass weight (HCW) was recorded immediately after slaughter. Carcasses were cooled for $24 \mathrm{~h}$ after harvest at $2.0^{\circ} \mathrm{C}$ and cold carcass weight (CCW), cold weight of the left half of the carcass (CLW), forequarter weight (FQW), rib weight (RW), and pistol hindquarter weight (PHW) were recorded. The carcasses were deboned $48 \mathrm{~h}$ after slaughter and carcass Longissimus thoracis muscle area (CLMA) at the 12th-13th rib interface was measured by tracing the outline of the muscle on acetate paper and then using a planimeter to determine the inscribed area. Carcass subcutaneous fat thickness (CFAT) at the 12th-13th rib interface was measured directly using a digital caliper.

The pistol hindquarter $(1020$, UNECE, 2004) was prepared from the entire hindquarter by removing the Thin flank, lateral portion of the ribs, and a portion of the Navel End Brisket (Handbook of Australian Meat, 2005) and trimming fat to approximately $3 \mathrm{~mm}$. Weights of the pistol hindquarter fat trim (PFATTR) and Eye of rump (2093), Inside (2010), Outside flat (2050), Eye of round (2040), Strip loin (2140), Tender loin (2150), Tri-tip (2131), Heel muscle (2364), Shin shank (1680), Knuckle (2070), and Rump cap (2091) were recorded (numeric codes for trade in brackets were produced according to United Nations Economic Commission for Europe Standard (UNECE, 2004). Weights of the individual cuts were summed (HQRTP), percentages of product (HQRTP \%), and fat of pistol hindquarter (PFATTR \%) were calculated relative to PHW.

\section{Statistical analysis}

Descriptive statistics were calculated using PROC MEANS of SAS (Statistical Analysis System, version 9.2). Regression analyses were conducted using the PROC GLMSELECT (SAS, version 9.2) with maximum partial $\mathrm{R}^{2}$ as the selection criterion. Significance levels of $p \leq$ 0.15 and $p \leq 0.10$ were required for a variable to enter and remain in the model, respectively. Two alternative sets of independent variables were evaluated: 1) "live measures" - SBW, ULMA, and UFAT; and 2) "carcass measures" - HCW, CLMA and CFAT. Root mean square error (RMSE) and Mallows $C_{p}$ (Mallows, 1973) statistics were used as additional indicators for the goodness of fit. When $\mathrm{C}_{p}$ values are graphed against the number of predictor variables $(p)$, the models with a little bias will tend to cluster near the line where $\mathrm{C}_{p}=p$ (Daniel and Wood, 1980). All models were validated using a k-fold cross validation $(\mathrm{n}=5)$ with Mallows $\mathrm{C}_{p}$ was used as a criterion in the model selection, and the CVPRESS statistics which the fitted model is used to compute the predicted residual sum of squares on the omitted part, this process is repeated for each $k$ fold and the sum of the $\mathrm{k}$ predicted residual sum of squares obtained is the estimate of prediction error, the cross validation is stopped when the CVPRESS statistics found the low value between the $k$ folds.

Determination of the required number of experimental units was calculated following MacNeil (1983),

$$
N=(3 t)^{2} /\left[\Delta / \sqrt{\left.\left(2-R_{i}^{2}\right) \sigma_{y}^{2}\right]^{2}},\right.
$$

where $t$ is the number of compared treatments, $\Delta$ is the difference in $\mathrm{Y}$ among any pair of SD differences 10.25 to $1 \mathrm{SD}), R_{i}^{2}$ is the coefficient of determination of model $i$ (Ultrasound model $\mathrm{R}^{2}=0.92$, Carcass $\mathrm{R}^{2}=0.97$, and actual empirical perfect model $\left.\mathrm{R}^{2}=1.0\right)$, and $\sigma_{y}^{2}$ is the variance of HQRTP trait.

Carcass and ultrasound equations with greatest $\mathrm{R}^{2}$, lower $\mathrm{C}_{\mathrm{p}^{\prime}}$ and lower RMSE for HQRTP and HQRTP $\%$ were used to calculate the required sample sizes. A conceptual model with perfect fit was used as comparison control to the proposed models, the perfect fit was adjusted using an empirical model with the model $\mathrm{R}^{2}$ $=1.0$, like a perfect prediction equation to predict the HQRTP and HQRTP \%.

\section{Results and Discussion}

Live and carcass measures averages and ranges (Table 1) are consistent with those of animals that are typically slaughtered in Brazil (Millen et al., 2009; Silva et al., 2012).

As expected, due to the part-whole relationship between them, prediction equations for FQW, RW, and PHW consistently had SBW or HCW as the most important independent variable (Table 2). Longissimus thoracis muscle area, whether measured using ultrasound was the second most important independent variable in 
Table 1 - Means, standard deviations, maximum and minimum values for ultrasound and carcass measurements based on data from 217 Braford steers.

\begin{tabular}{lrrrr}
\hline Trait ${ }^{2}$ & Mean & SD & Minimum & Maximum \\
\hline Live measures & & & & \\
\hline SBW, kg & 400.27 & 82.60 & 245.00 & 565.00 \\
UFAT, mm & 3.86 & 1.40 & 1.00 & 8.30 \\
ULMA, cm ${ }^{2}$ & 60.94 & 8.66 & 41.29 & 87.70 \\
URPFAT, mm & 6.55 & 2.23 & 2.30 & 13.46 \\
UGM, mm & 85.11 & 9.19 & 70.20 & 114.10 \\
\hline Carcass Measures & & & & \\
\hline HCW, kg & 208.64 & 42.07 & 130.20 & 294.50 \\
CFAT, mm & 3.98 & 1.55 & 1.40 & 10.10 \\
CLMA, cm & 60.57 & 8.93 & 40.63 & 89.00 \\
FQW, kg & 38.96 & 7.54 & 23.80 & 58.06 \\
RW, kg & 14.58 & 3.95 & 6.20 & 23.10 \\
PHW, kg & 49.00 & 9.63 & 31.50 & 67.50 \\
INW, kg & 6.65 & 1.48 & 3.92 & 10.33 \\
OUTW, kg & 3.78 & 1.04 & 2.08 & 7.39 \\
ERUW, kg & 2.86 & 0.74 & 1.47 & 4.59 \\
RCW, kg & 1.34 & 0.29 & 0.74 & 2.15 \\
KNW, kg & 4.00 & 0.94 & 2.12 & 6.01 \\
TTW, kg & 1.00 & 0.25 & 0.52 & 1.60 \\
EROW, kg & 1.80 & 0.44 & 1.06 & 4.46 \\
SSW, kg & 2.16 & 0.45 & 1.29 & 3.77 \\
STLW, kg & 7.20 & 1.30 & 4.21 & 10.72 \\
HLW, kg & 1.84 & 0.21 & 1.08 & 2.55 \\
TLW, kg & 1.49 & 0.40 & 0.81 & 2.90 \\
HQRTP, kg & 33.81 & 7.12 & 20.85 & 49.25 \\
PFATR, kg & 4.29 & 0.82 & 2.44 & 6.50 \\
HQRTP\% & 69.20 & 2.07 & 64.04 & 74.78 \\
PFATR\% & 9.10 & 2.21 & 4.34 & 14.56 \\
\hline ISBW $=5 h$ & & & & \\
\hline
\end{tabular}

${ }^{1}$ SBW $=$ shrunk body weight 12 -h fast; UFAT = ultrasound subcutaneous fat thickness between the $12^{\text {th }}-13^{\text {th }}$ ribs; ULMA $=$ ultrasound Longissimus thoracis muscle area between the $12^{\text {th }}-13^{\text {th }}$ ribs; URPFAT = ultrasound rump fat thickness; UGM = ultrasound Gluteus medius depth; HCW = hot carcass weight; CFAT $=$ carcass subcutaneous fat thickness between the $12^{\text {th }}$ and the $13^{\text {th }}$ ribs; CLMA $=$ carcass Longissimus thoracis muscle area between the $12^{\text {th }}$ and the $13^{\text {th }}$ ribs; $\mathrm{FQW}=$ forequarter weight; $\mathrm{RW}=$ rib weight, $\mathrm{PHW}=$ pistola hindquarter weight (1020); INW = Inside weight (2010), OUTW = outside flat weight (2050); ERUW = Eye rump weight (2093), RCW = Rump cap weight (2091), KNW = Knucle weight (2070), TTW = Tri-tip weight (2131); EROW = Eye round weight (2040), SSW = Shin shank weight (1680); STLW = Strip loin weight (2140); HLW = Heel muscle weight (2364), TLW = Tender loin weight (2150); HQRTP = pistol hindquarter weight of retail product, and PFATR = pistol hindquarter fat trim; HQRTP\% = pistol hindquarter percentage of retail product, PFATR\% = pistol hindquarter fat percentage. Numeric codes for trade (in brackets) are according United Nations Economic Commission for Europe Standard (UNECE, 2004).

the prediction of FQW and PHW. However, for RW, the subcutaneous fat thickness was consistently the second most important independent variable. The addition of ULMA and UFAT variables to the regressions of PHW and RW on live measures did not result in large increases in $\mathrm{R}^{2}$ but did lead to reduced lack of fit $\left(\mathrm{C}_{\mathrm{p}} \approx \mathrm{p}\right)$ and reduced residual variance.

Equations of FQW and PHW with carcass measures as independent variables fit better based on $\mathrm{R}^{2}$, $\mathrm{C}_{\mathrm{p}^{\prime}}$ and RMSE than equations with live measures as in- dependent variables (Table 2). However, even the latter equations explained greater than $90 \%$ of the variation in these traits. Most previous attempts to predict weight or percentage of retail product from the pistol hindquarter have found carcass measures to be the more accurate predictors (Tarouco et al., 2007; Silva et al., 2012).

Both here and in Hassen et al. (1999), SBW of the live animal was found to be the most valuable predictor of HCW (Table 3). This was undoubtedly due to the very substantial part-whole relationship of HCW and SBW. In the present study, SBW explained $95 \%$ of the variation in HCW. However, as in Hassen et al. (1999), the univariate regression model had considerable a lack of fit. Adding other indicators of muscularity and fatness to the prediction equation reduced the lack of fit to a more acceptable level while resulting in only minor improvements in RMSE and $\mathrm{R}^{2}$.

The equation for predicting HQRTP using live measures was substantially similar to that for prediction of HCW (Table 3). This is again expected, as HQRTP is a substantial portion of HCW. Previous studies have found fat depth measured with ultrasound to be an important predictor of HQRTP (Greiner et al., 2003; Tarouco et al., 2007; Silva et al., 2012; Sakamoto et al., 2014). In the present study, a positive relationship was observed between HQRTP and UFAT, demonstrating that the first variable increases as consequence of the increase of the second. Studies in which the amount of subcutaneous fat are high, the sign of coefficients are negative in relation to the amount of HQRTP (Silva et al., 2012; Sakamoto et al., 2014), as well as the amount of wholesale retail product (Greiner et al., 2003; Sakamoto et al., 2014). However, when the subcutaneous fat are low, the sign of coefficient change for a positive influence for HQRTP (0.150) as demonstrated by Tarouco et al. (2007). It can be explained because adipose is commonly the most variable tissue and its deposition is affected by breed and nutrition (Berg and Butterfield, 1976).

The present study and those cited above vary in both of these regards, perhaps indicating a need for different equations to account for these circumstances or, at a minimum, validation of any more broadly purposed equation. The equation for predicting HQRTP from carcass measures was qualitatively similar to its counterpart using live measures, but only $5 \%$ more accurate.

In the 5-fold cross-validation exercise, the equations developed here were shown to be robust, as they, on average, explained $92 \%$ of the variation in HQRTP trait by ultrasound equation and $97 \%$ by carcass equation in the $1 / 5$ th of the data that was held apart for the estimation process (Table 3).

While finding significant partial regression coefficients for prediction of UFAT from live measures, the best equation developed here explained less than $15 \%$ of the variation in it (Table 3). This may be due to UFAT being a relatively small component of HCW. Moreover, prediction of FAT from carcass measures was similar to live measures (Table 3). However, previous studies have 
Table 2 - Prediction equations for weights of forequarter, rib, and pistol hindquarter from live and carcass measures based on data from 217 Braford steers.

\begin{tabular}{|c|c|c|c|c|c|c|c|}
\hline Dependent variables ${ }^{1}$ & Independent variable² & Entry order & Intercept & Regression coefficient ${ }^{3}$ & $\mathrm{RMSE}^{4}$ & Cumulative $\mathrm{R}^{2}$ & $\mathrm{C}_{p}$ \\
\hline \multirow[t]{2}{*}{ FQW, kg } & SBW, kg & 1 & 1.664 & 0.081 & 2.241 & 0.91 & 10.55 \\
\hline & ULMA, $\mathrm{cm}^{2}$ & 2 & & 0.078 & 2.196 & 0.91 & 2.63 \\
\hline \multirow[t]{2}{*}{ RW, kg } & SBW, kg & 1 & -5.002 & 0.044 & 1.339 & 0.88 & 65.17 \\
\hline & UFAT, mm & 2 & & 0.461 & 1.175 & 0.91 & 2.26 \\
\hline \multirow[t]{3}{*}{ PHW, kg } & SBW, kg & 1 & -1.364 & 0.101 & 2.642 & 0.92 & 27.71 \\
\hline & ULMA, $\mathrm{cm}^{2}$ & 2 & & 0.137 & 2.616 & 0.93 & 13.63 \\
\hline & UFAT, mm & 3 & & 0.435 & 2.493 & 0.93 & 4.00 \\
\hline \multirow[t]{3}{*}{ FQW, kg } & HCW, kg & 1 & 3.947 & 0.182 & 1.472 & 0.96 & 13.68 \\
\hline & CFAT, mm & 2 & & -0.268 & 1.439 & 0.96 & 5.40 \\
\hline & CLMA, kg & 3 & & -0.032 & 1.430 & 0.96 & 4.00 \\
\hline \multirow[t]{2}{*}{ RW, kg } & HCW, kg & 1 & -4.716 & 0.086 & 1.275 & 0.90 & 27.19 \\
\hline & CFAT, mm & 2 & & 0.291 & 1.201 & 0.91 & 3.00 \\
\hline PHW, kg & $\mathrm{HCW}, \mathrm{kg}$ & 1 & 2.143 & 0.225 & 1.319 & 0.98 & 3.44 \\
\hline
\end{tabular}

Table 3 - Prediction equations for hot carcass, retail product, and trimmed fat weights based on data from 217 Braford steers.

\begin{tabular}{|c|c|c|c|c|c|c|c|}
\hline Dependent variables ${ }^{1}$ & Independent variable ${ }^{2}$ & Entry order ${ }^{3}$ & Intercept & Regression coefficient & $\mathrm{RMSE}^{4}$ & Cumulative $\mathrm{R}^{2}$ & $C_{p}$ \\
\hline \multicolumn{8}{|l|}{ Live measures } \\
\hline \multirow[t]{3}{*}{ HCW, kg } & SBW, kg & 1 & -11.556 & 0.459 & 9.103 & 0.95 & 34.229 \\
\hline & ULMA, $\mathrm{cm}^{2}$ & 2 & & 0.477 & 8.919 & 0.95 & 21.68 \\
\hline & UFAT, mm & 3 & & 1.894 & 8.489 & 0.96 & 4.00 \\
\hline \multirow[t]{3}{*}{ HQRTP, kg } & SBW, kg & 1 & -4.236 & 0.067 & 2.190 & 0.90 & 46.35 \\
\hline & ULMA, $\mathrm{cm}^{2}$ & 2 & & 0.165 & 2.190 & 0.92 & 9.26 \\
\hline & UFAT, mm & 3 & & 0.282 & 1.981 & 0.92 & 4.00 \\
\hline \multirow[t]{2}{*}{ FAT,kg } & UFAT, mm & 1 & 3.064 & 0.169 & 0.819 & 0.09 & 6.54 \\
\hline & SBW, kg & 2 & & 0.001 & 0.787 & 0.11 & 4.02 \\
\hline HQRTP \% & ULMA, $\mathrm{cm}^{2}$ & 1 & 61.865 & 0.122 & 1.797 & 0.25 & 1.08 \\
\hline \multirow[t]{2}{*}{ PFATR $\%$} & SBW, kg & 1 & 15.432 & -0.018 & 1.588 & 0.48 & 2.00 \\
\hline & UFAT, mm & 2 & & 0.253 & 1.553 & 0.51 & 7.12 \\
\hline \multicolumn{8}{|l|}{ Carcass measures } \\
\hline \multirow[t]{3}{*}{ FAT, kg } & CFAT, mm & 1 & 3.990 & 0.105 & 0.799 & 0.09 & 11.42 \\
\hline & HCW, kg & 2 & & 0.006 & 0.770 & 0.11 & 9.41 \\
\hline & CLMA, $\mathrm{cm}^{2}$ & 3 & & -0.025 & 0.758 & 0.14 & 4.00 \\
\hline \multirow[t]{2}{*}{ HQRTP, kg } & HCW, kg & 1 & -2.703 & 0.148 & 1.304 & 0.96 & 47.86 \\
\hline & CLMA, $\mathrm{cm}^{2}$ & 2 & & 0.092 & 1.174 & 0.97 & 3.72 \\
\hline HQRTP \% & CLMA, $\mathrm{cm}^{2}$ & 1 & 61.71 & 0.125 & 1.756 & 0.28 & 4.86 \\
\hline \multirow[t]{2}{*}{ PFATR \% } & HCW, kg & 1 & 18.187 & -0.025 & 1.614 & 0.47 & 2.00 \\
\hline & CLMA, $\mathrm{cm}^{2}$ & 2 & & -0.063 & 1.569 & 0.50 & 3.00 \\
\hline
\end{tabular}

${ }^{1} \mathrm{HCW}=$ hot carcass weight; HQRTP $=$ pistol hindquarther retail product weight; $\mathrm{FAT}=$ weights of the fat trim. ${ }^{2 \mathrm{HQRTP}} \%=$ pistol hindquarter percentage of retail product; PFATR $\%=$ pistol hindquarter fat percentage. SBW = shrunk body weight; ULMA = ultrasound Longissimus thoracis muscle area between the $12^{\text {th }}$ and the $13^{\text {th }}$ ribs; and UFAT = subcutaneous fat thickness between the $12^{\text {th }}$ and $13^{\text {th }}$ ribs. ${ }^{3}$ Regression coefficient, RMSE, R2, and $C_{p}$, are updated in respect to a new independent variable to the prediction equation, the new independent variable is additionally in respect to the $\mathrm{C}_{\mathrm{p}} \approx \mathrm{p}$ independent variables, and ${ }^{4}$ Root-mean-square error.

found fat depth to be an important predictor of FAT (Perkins et al., 1992; Robinson et al., 1992; Bergen et al., 2005; Sakamoto et al., 2014). The discrepancy between the present study and those conducted previously may be due to the relative leanness of the cattle in this study. In studies where cattle were finished on high feed concentrate rations prior to harvest and fat deposition was greater, prediction equations that used traits measure with ultrasound as independent variables were more accurate than was found in the present research (Herring et al., 1994; Realini et al., 2001; Silva et al., 2012). Therefore, the FAT thickness should be considered when using predictions equations that were developed from cattle that were reared in different production systems. 
In the prediction of weights of individual commercial cuts, models based on carcass measures explained a greater proportion of variability than models that used live measures as independent variables (Tables 4 and 5). Either SBW or HCW was almost invariably the first independent variable to enter the regression model. Likewise, Tarouco et al. (2007) and Silva et al. (2012) among others all support the primary importance of body weight in the prediction of weights of HQRTP. Similarly, Huerta-Leidenz et al. (2018) found that HCW was the first variable in importance in regression models to explain HQRTP. Other traits that entered the models accounted for relatively little additional variation but improved goodness-of-fit. These equations consistent failed to attain the accuracy of prediction for HQRTP. Fabrication of individual cuts can introduce error due to variation in deboning and fat trimming (Tarouco, et al., 2007). Fat trim also varies among cuts with the level of trim changing nonlinearly with increasing fatness (Strydom and Smith, 2005).

There is also interest in yield (composition) of the carcass and retail product. Despite longstanding recognition of the inadequacy of percentages as measures of composition (Weil, 1962; Miller and Weil, 1963; Dinkel et al., 1965; Sakamoto et al., 2014; Huerta-Leidenz et al., 2018), such practice has been commonplace in studies similar to this one. Here, use of regression on SBW or HCW with variation in the deviations from the regression is advocated as being indicative of differences among animals in composition.
Sample size in carcass studies does not have information available. The sample size is the main problem when carcass studies are performed, not only for research but also for the industry. Studies that have provided predictions of an amount and a yield of carcass cuts from live and ultrasound measurements perform both carcass and ultrasound data (Tait et al., 2005; Tarouco et al., 2007; Silva et al., 2012; Sakamoto et al., 2014; Huerta-Leidenz et al., 2018), however, the number of animals necessary to do the researches are high (102 to 466 ) and the sample size to determine the maximum model fit was not determinate.

Generally, carcass and ultrasound data show a similarly coefficient of determination with weight of edible cuts, however, when data were presented as a percentage basis the relationship become weaker (Dinkel et al., 1965; Tarouco et al., 2007; Silva et al., 2012; Sakamoto et al., 2014; Huerta-Leidenz et al., 2018). The authors consider unnecessary the estimate the sample size of HQRTP \% because the low model fit to this trait (data not showed).

The sample size required to detect a difference in HQRTP between two treatments means, by considering $\alpha=0.05$, differences from 0.25 standard deviations $(1.780 \mathrm{~kg})$ to 1.00 standard deviations $(7.120 \mathrm{~kg})$ and power of the test equal to 0.80 , are shown in Figure 1. To detect a difference of $1.780 \mathrm{~kg}$ in carcass HQRTP, the numbers of animals required would be: 622 scanned by ultrasound, 593 carcasses measured for HCW and CLMA, and 576 fabricated into product. Thus, in this

Table 4 - Multiple regression equations for prediction of commercial cut weights from the pistol hindquarter using ultrasound measures based on data from 217 Braford steers.

\begin{tabular}{|c|c|c|c|c|c|c|c|}
\hline${ }^{1}$ Dependent variable & ${ }^{2}$ Independent variable & ${ }^{3}$ Entry order & Intercept & Regression coefficient & $\mathrm{RMSE}^{4}$ & Cumulative $\mathrm{R}^{2}$ & $\mathrm{C}_{p}$ \\
\hline \multirow[t]{2}{*}{ INW, kg } & SBW, kg & 1 & -0.494 & 0.014 & 0.622 & 0.82 & 13.29 \\
\hline & ULMA, $\mathrm{cm}^{2}$ & 2 & & 0.024 & 0.607 & 0.83 & 3.85 \\
\hline \multirow[t]{2}{*}{ OUTW, kg } & SBW, kg & 1 & -0.114 & 0.009 & 0.496 & 0.77 & 10.20 \\
\hline & ULMA, $\mathrm{cm}^{2}$ & 2 & & 0.018 & 0.485 & 0.78 & 2.65 \\
\hline \multirow[t]{2}{*}{ ERUW, kg } & SBW, kg & 1 & -0.814 & 0.007 & 0.241 & 0.89 & 17.84 \\
\hline & ULMA, $\mathrm{cm}^{2}$ & 2 & & 0.011 & 0.232 & 0.90 & 2.79 \\
\hline \multirow[t]{2}{*}{ RCW, kg } & SBW, kg & 1 & 0.280 & 0.002 & 0.219 & 0.42 & 23.73 \\
\hline & UFAT, mm & 2 & & 0.051 & 0.208 & 0.48 & 2.27 \\
\hline \multirow[t]{3}{*}{ TTW, kg } & SBW, kg & 1 & -0.254 & 0.002 & 0.123 & 0.76 & 14.05 \\
\hline & ULMA, $\mathrm{cm}^{2}$ & 2 & & 0.017 & 0.123 & 0.77 & 9.34 \\
\hline & UFAT, mm & 3 & & 0.004 & 0.120 & 0.78 & 4.00 \\
\hline \multirow[t]{2}{*}{ KNW, kg } & SBW, kg & 1 & -0.580 & 0.009 & 0.381 & 0.83 & 12.34 \\
\hline & ULMA, $\mathrm{cm}^{2}$ & 2 & & 0.015 & 0.372 & 0.84 & 2.68 \\
\hline \multirow[t]{2}{*}{ EROW, kg } & SBW, kg & 1 & -0.180 & 0.003 & 0.262 & 0.65 & 8.99 \\
\hline & ULMA, $\mathrm{cm}^{2}$ & 2 & & 0.009 & 0.257 & 0.66 & 2.30 \\
\hline \multirow[t]{2}{*}{ STLW, kg } & ULMA, $\mathrm{cm}^{2}$ & 1 & -1.591 & 0.076 & 0.978 & 0.36 & 25.44 \\
\hline & SBW, kg & 2 & & 0.009 & 0.851 & 0.46 & 3.35 \\
\hline \multirow[t]{2}{*}{ TLW, kg } & SBW, kg & 1 & -0.431 & 0.003 & 0.211 & 0.72 & 13.63 \\
\hline & ULMA, $\mathrm{cm}^{2}$ & 2 & & 0.009 & 0.205 & 0.74 & 2.19 \\
\hline
\end{tabular}

${ }^{1} \mathrm{NNW}=$ Inside weight; OUTW = Outside flat weight; ERUW = Eye rump weight; RCW = Rump cap weight; TTW = Tri-tip weight; KNW = Knucle weight; EROW = Eye round weight; STLW = Strip loin weight; TLW = Tender loin weight. ${ }^{2} \mathrm{SBW}=$ shrunk body weight; ULMA = ultrasound Longissimus thoracis muscle area between the $12^{\text {th }}$ and the $13^{\text {th }}$ ribs; and UFAT = subcutaneous fat thickness between the $12^{\text {th }}$ and $13^{\text {th }}$ ribs. ${ }^{3}$ Regression coefficient, RMSE, $\mathrm{R}^{2}$, and $\mathrm{C}$, are updated in respect to a new independent variable to the prediction equation, the new independent variable is additionally in respect to the $C_{p} \approx p$ independent variables, and ${ }^{4}$ Root-mean-square error. 
Table 5 - Multiple regression equations for prediction of commercial cut weights from the pistol hindquarter using carcass measures based on data from 217 Braford steers.

\begin{tabular}{|c|c|c|c|c|c|c|c|}
\hline Dependent variable $^{1}$ & Independent variable ${ }^{2}$ & Entry order ${ }^{3}$ & Intercept & Regression coefficient & $\mathrm{RMSE}^{4}$ & Cumulative $\mathrm{R}^{2,5}$ & $C_{p}$ \\
\hline \multirow[t]{2}{*}{ INW, kg } & $\mathrm{HCW}, \mathrm{kg}$ & 1 & -0.427 & 0.030 & 0.503 & 0.88 & 3.60 \\
\hline & CLMA, $\mathrm{cm}^{2}$ & 2 & & 0.010 & 0.499 & 0.89 & 2.02 \\
\hline \multirow[t]{2}{*}{ OUTW, kg } & HCW, kg & 1 & -1.162 & 0.019 & 0.448 & 0.81 & 6.72 \\
\hline & CLMA, $\mathrm{cm}^{2}$ & 2 & & 0.013 & 0.441 & 0.82 & 2.07 \\
\hline \multirow[t]{3}{*}{ ERUW, kg } & HCW, kg & 1 & -0.728 & 0.016 & 0.192 & 0.93 & 14.09 \\
\hline & CLMA, $\mathrm{cm}^{2}$ & 2 & & 0.005 & 0.187 & 0.93 & 10.72 \\
\hline & CFAT, mm & 3 & & -0.017 & 0.186 & 0.94 & 3.24 \\
\hline \multirow[t]{2}{*}{ RCW, kg } & HCW, kg & 1 & 0.289 & 0.004 & 0.214 & 0.46 & 26.48 \\
\hline & CFAT, mm & 2 & & 0.049 & 0.201 & 0.53 & 2.00 \\
\hline \multirow[t]{2}{*}{ TTW, kg } & HCW, kg & 1 & -0.197 & 0.005 & 0.106 & 0.82 & 5.66 \\
\hline & CLMA, $\mathrm{cm}^{2}$ & 2 & & 0.002 & 0.105 & 0.83 & 2.87 \\
\hline \multirow[t]{2}{*}{ KNW, kg } & HCW, kg & 1 & -0.573 & 0.019 & 0.301 & 0.90 & 5.48 \\
\hline & CLMA, $\mathrm{cm}^{2}$ & 2 & & 0.008 & 0.297 & 0.90 & 2.00 \\
\hline \multirow[t]{2}{*}{ EROW, kg } & HCW, kg & 1 & 0.035 & 0.009 & 0.229 & 0.73 & 8.80 \\
\hline & CFAT, mm & 2 & & -0.029 & 0.226 & 0.74 & 3.41 \\
\hline \multirow[t]{3}{*}{ STLW, kg } & CLMA, $\mathrm{cm}^{2}$ & 1 & -0.234 & 0.055 & 1.010 & 0.36 & 33.56 \\
\hline & HCW, kg & 2 & & 0.021 & 0.875 & 0.44 & 15.01 \\
\hline & CFAT, mm & 3 & & -0.190 & 0.834 & 0.50 & 4.00 \\
\hline \multirow[t]{2}{*}{ TLW, kg } & HCW, kg & 1 & -0.421 & 0.007 & 0.189 & 0.78 & 9.48 \\
\hline & CLMA, $\mathrm{cm}^{2}$ & 2 & & 0.006 & 0.185 & 0.79 & 2.13 \\
\hline
\end{tabular}

${ }^{1} \mathrm{NNW}=$ Inside weight; OUTW = Outside flat weight; ERUW = Eye rump weight; RCW = Rump cap weight; TTW = Tri-tip weight; KNW = Knucle weight; EROW = Eye round weight; STLW = Strip loin weight; TLW = Tender loin weight. ${ }^{2 \mathrm{HCW}}=$ hot carcass weight; CLMA = carcass Longissimus thoracis muscle area between the $12^{\text {th }}$ and the $13^{\text {th }}$ ribs; and CFAT = subcutaneous fat thickness between the $12^{\text {th }}$ and $13^{\text {th }}$ ribs. ${ }^{3 R e g r e s s i o n}$ coefficient RMSE, $\mathrm{R}^{2}, \mathrm{C}_{p}$, and $p$-value are updated in respect to a new independent variable to the prediction equation, the new independent variable is additionally in respect to the $C_{p} \approx p$ independent variables, and ${ }^{4}$ Root-meansquare error, and ${ }^{5}$ Cumulative $\mathrm{R}^{2}$.

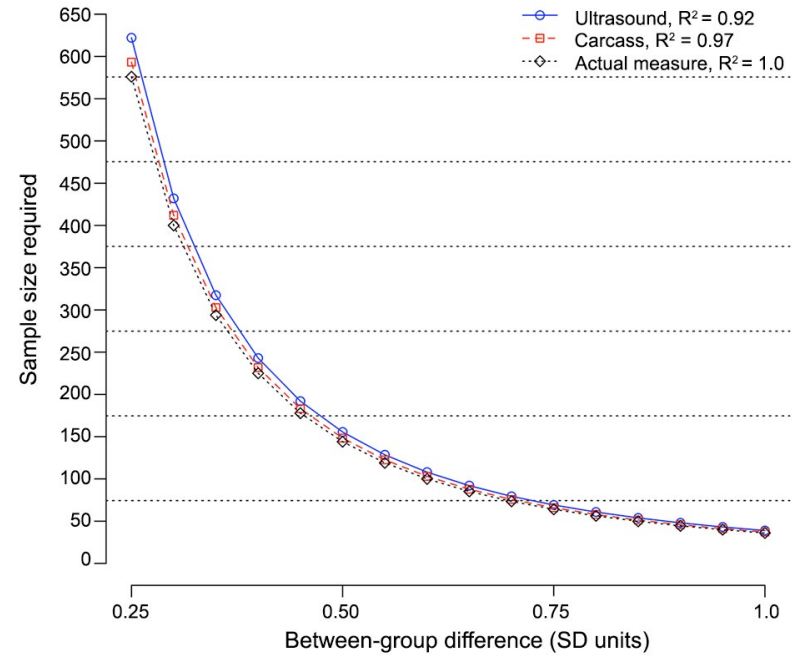

Figure 1 - Sample sizes required for detect $(\alpha=0.05)$ a difference in weight of retail product from the pistol hindquarter HQRTP between two treatments over a range of critical effect sizes from 0.25 to 1.00 standard deviations (SD $=7.120 \mathrm{~kg}$ ) with power-ofthe test equal to 0.80 for carcasses of 130 to $294 \mathrm{~kg}$.

case, ultrasonic measurement of live animals increases the required sample sizes for experiments of equal inferential power by 5 and $7 \%$ compared to those using carcass indicators and direct HQRTP measures (by model with $\mathrm{R}^{2}=1.0$ ).
As the critical difference between treatments increases, the number of animals required decreases substantially. For example, the sample size to detect a difference between treatments of 1.00 SD in HQRTP was 39 when using live measures, 37 when using carcass measures, and 36 when the product was fabricated. If the desired inference were to yield of product rather than to its mass, the standard deviation that is appropriate to experimental planning is reduced to the degree that variation in HQRTP. As these experiments are equivalent in inferential power, efficient use of resources obligates the least cost paradigm. Numerous equations were identified for a large number of different end points under widely varying sets of experiments (Hedrick, 1983, Tait et al., 2005; Silva et al., 2012; Sakamoto et al., 2014; Huerta-Leidenz et al., 2018).

As the direct measurements of composition requires the animal death, the dissection or the debone methods are not suitable for selection or replacement animals or for time series data and the prediction of body composition can be obtained in a less costly and nondestructive manner. In the cost benefit analysis to decide whether or not to utilize a prediction equation, the value of this additional information should be viewed as a benefit of the direct measurement of dependent variable (MacNeil, 1983). Additionally, the reduction of the number of experimental units justify the use of techniques that are in agreement with the 
reduction principle and the use of methods that minimize the number of experimental units, reduce negligible damage, and distress, to the great benefit of their accuracy (Russell and Burch, 1959).

\section{Conclusions}

Results of this study demonstrates that ultrasound may be used to estimate the weight of pistol hindquarter cuts with only a slight degradation of accuracy relative to the use of carcass measures. Thus, in many circumstances it is possible to replace post-slaughter carcass measurement for pre-slaughter ultrasound measurements. Models for individual cuts weights that used traits measured with ultrasound as independent variables approached the accuracy of models using carcass traits. Slightly greater samples sizes were required to have equivalent power to detect differences in retail product weights using ultrasound measures as compared to carcass traits.

\section{Acknowledgements}

We acknowledge the Guatambu Farm, especially Valter José Pötter owner of the farm and who managed the animals and Marfrig Group responsible for the slaughter and collection of data for this study. Support for L.L.C. from grant of Coordenação de Aperfeiçoamento de Pessoal de Nivel Superior (CAPES). Support for M.D.M. from Conselho Nacional de Desenvolvimento Científico e Tecnológico (CNPq-CSFPVE) grant 303423/2014-5 as a component of the Brazilian Science Without Borders Program is gratefully appreciated.

\section{Authors' Contributions}

Conceptualization: Cardoso, L.C.; Tarouco, J.U.; MacNeil, M.D. Data acquisition: Cardoso, L.C.; Tarouco, J.U.; Lobato, J.F.P.; Dambrós, M.C.; Freitas, A.K.; Devincenzi, T.; Feijó, F.D. Design of Methodology: Cardoso, L.C.; Tarouco, J.U.; MacNeil, M.D.; Cardoso, F.F. Writing and editing: Cardoso, L.C.; Tarouco, J.U.; MacNeil, M.D.; Cardoso, F.F.

\section{References}

Berg, R.T; Butterfield, R.M. 1976. New Concepts of Cattle Growth. Sydney University Press, Sydney, Australia.

Bergen, R.D.; Miller, S.P.; Mandell, I.B.; Robertson, W.M. 2005. Use of live ultrasound, weight and linear measurements to predict carcass composition of young beef bulls. Canadian Journal of Animal Science 85: 23-35.

Daniel, C.; Wood, F.S. 1980. Fitting Equations to Data. 2ed. John Wiley, New York, NY, USA.

Dinkel, C.A.; Wilson, L.L.; Tuma, H.J.; Minyard, J.A. 1965. Ratios and percents as measures of carcass traits. Journal of Animal Science 24: 425-429.
Federation of Animal Science Societies [FASS]. 2010. Guide for the Care and Use of Agricultural Animals in Research and Teaching. 3ed. FASS, Champaign, IL, USA.

Festing, M.F.W.; Altman, D.G. 2002. Guidelines for design and statistical analysis of experiments using laboratory animals. ILAR Journal 43: 244-258.

Greiner, S.P.; Rouse, G.H.; Wilson, D.E.; Cundiff, L.V.; Wheeler, T.L. 2003. Accuracy of prediction weight and percentage of beef carcass retail product using ultrasound and live animal measures. Journal of Animal Science 81: 466-473.

Handbook of Australian Meat. 2005, 7ed. Aus-Meat, Murarrie, Australia.

Hassen, A.; Wilson, D.E.; Rouse, G.H. 1999. Evaluation of carcass, live, and real-time ultrasound measures in feedlot cattle. I. Assessment of sex and breed effects. Journal of Animal Science 77: 273-282.

Hedrick, H.B. 1983. Methods of estimating live animal and carcass composition. Journal of Animal Science 57: 1316-1327.

Herring, W.O.; Bertrand, J.K.; Benyshek, L.L.; Miller, D.C. 1994. Comparison of live and carcass equations prediction percentage of cutability, retail product weight and trimmable fat in beef cattle. Journal of Animal Science 72: 1107-1118.

Hopkins, D.L.; Roberts, A.H.K. 1995. The value of carcass weight, fat depth measures and eye muscle area for predicting the percentage yield of saleable meat in Australian grass-fed beef carcasses for Japan. Meat Science 41: 137-145.

Huerta-Leidenz, N.; Atencio-Valladares, O.; Rodriguez, J.; Jerez-Timaure, N.; Vargas, G.; Rodas-González, A. 2018. Predictability of lean product, bone, and fat trim in beef carcasses from Costa Rica. Meat Science 143: 223-229.

Jardim, P.O.C; Dode, M.A.; Osório, J.C.S.; Lüder, W.E. 1991. Estimation of physical composition in carcasses of Holstein Steers. Pesquisa Agropecuária Brasileira 26: 1193-1199 (in Portuguese, with abstract in English).

Kerth, C.R.; Braden, K.W.; Cox, R.; Kerth, L.K.; Rankins Jr, D.L. 2007. Carcass, sensory, fat color, and consumer acceptance characteristics of Angus-cross steers finished on ryegrass (Lolium multiflorum) forage or on a high-concentrate diet. Meat Science 75: 324-331.

MacNeil, M.D. 1983. Choice of a prediction equation and the use of the selected equation in subsequent experimentation. Journal of Animal Science 57: 1328-1336.

MacNeil, M.D.; Northcutt, S. 2008. National cattle evaluation system for combined analysis of carcass characteristics and indicator traits recorded by using ultrasound in Angus cattle. Journal of Animal Science 86: 2518-2524.

Mallows, CL. 1973. Some comment on Cp. Technometrics 8: 661-675.

Mark, T.; Fikse, W.F., Sullivan, P.G.; VanRaden, P.M. 2007. Prediction of genetic correlations and international breeding values for missing traits. Journal of Dairy Science 90: 4805-4813.

Millen, D.D.; Pacheco, R.D.L.; Arrigoni, M.D.B.; Galyen, M.L.; Vasconcelos, J.T. 2009. A snapshot of management practices and nutritional recommendations used by feedlot nutritionists in Brazil. Journal of Animal Science 87: 3427-3439.

Miller, I.; Weil Jr., W.B. 1963. Some problems in expressing and comparing body composition determined by direct analysis. Annals of the New York Academy of Sciences 110: 153-160. 
Perkins, T.L.; Green, R.D.; Hamlin, K.E. 1992. Evaluation of ultrasonic estimates of carcass fat thickness and Longissimus muscle area in beef cattle. Journal of Animal Science 70: 10021010.

Realini, C.E.; Williams, R.E.; Pringle, T.D.; Bertrand, J.K. 2001. Gluteus medius and rump fat depths as additional live animal ultrasound measurements for predicting retail product and trimmable fat in beef carcasses. Journal of Animal Science 7: 378-1385.

Robinson, D.L.; McDonald, C.A.; Hammond, K.; Turner, J.W. 1992. Live animal measurement of carcass traits by ultrasound: assessment and accuracy of sonographers. Journal of Animal Science 70: 1667-1676.

Russell, W.M.S; Burch, R.L. 1959. The Principles of Humane Experimental Technique. Universities Federation for Animal Welfare, London, UK.

Sakamoto, L.S.; Mercadante, M.E.Z.; Bonilha, S.F.M.; Branco, R.H.; Bonilha, E.F.M.; Magnani, E. 2014. Prediction of retail beef yield and fat content from live animal and carcass measurements in Nellore cattle. Journal of Animal Science 92: 5230-5238.

Silva, S.L.; Tarouco, J.U.; Ferraz, J.B.S.; Gomes, R.C.; Leme, P.R.; Navajas, E.A. 2012. Prediction of retail beef yield, trim fat and proportion of high-valued cuts in Nellore cattle using ultrasound live measurements. Brazilian Journal of Animal Science 41: 2025-2031.
Strydom, P.E., Smith, M.F. 2005. Predicting yields of high priced trimmed beef cuts by means of carcass weight and visual assessments of fat cover and conformation. South African Journal of Animal Science 35: 195-205.

Tait, R.G. Jr.; Wilson, D.; Rouse, G. 2005. Prediction of retail product and trimmable fat yields from the four primal cuts. Journal of Animal Science 83: 1356-1360.

Tarouco, J.U.; Lobato, J.F.P.; Tarouco, A.K.; Massia, G.I.S. 2007. Comparison between ultrasonic and carcass measures in body composition prediction in cattle: prediction of weight and percentage hind-quarter retail products. Brazilian Journal of Animal Science 36: 2092-2101 (in Portuguese, with abstract in English).

Teira, G.A.; Tinois, E.; Lotufo, R.A.; Felício, P.E. 2003. Digitalimage analysis to predict weight and yields of boneless subprimal beef cuts. Scientia Agricola 60: 403-408.

United Nations of Economic Commission for Europe. [UNECE]. 2004. UNECE Standard bovine meat carcasses and cuts. (Document ECE/TRADE/326). [Available at: https://www. unece.org/fileadmin/DAM/trade/agr/standard/meat/e/ Bovine_2004_e_Publication.pdf [Accessed Nov 11, 2017]

Weil Jr., W.B. 1962. Adjustment for size: a possible misuse of ratios. American Journal of Clinical Nutrition 11: 249-252. 